\title{
Grey Correlation Analysis between Industrial Structures and Carbon Emission in Guangxi Beibu Gulf Economic Zone
}

\author{
Zhang Fang ${ }^{1,2}$ \\ 1. Business College of Central South University, Changsha 410083, China \\ 2. Party School of Guangxi Zhuang Autonomous Region Committee of CPC, \\ Nanning 530021, China \\ 920747994@qq.com
}

\begin{abstract}
Industrial restructuring is an important step to realize low-carbon economic development in Guangxi Beibu Gulf Economic Zone. This pâper explores the relationship between industrial structures and carbon emission by analyzing development of industrial structures and low-carbon economy, status of carbon emission and grey correlation between industrial structures and carbon emission in the zome. The conclusion is that there is a close relationship between industrial structures and carbon emission and that secondary industries have the most importan influence on carbon emission intensity in the economic zone. On this basis, suggestions are provided to promote development of low-carbon economy.
\end{abstract}

Keywords: Low carbon ecón\&my; Industriatstructures; Carbon emission; Grey correlation analysis

\section{Introduction}

Global warming has become fan overarching concern for every country in the world since publication of the third climate evaluation report by IPCC in 2001. IPCC claimed in the fourth publication in 2007 that greenhouse gases discharged by human consumption of energy accounted for over $90 \%$ of global warming. Thus developing low-carbon economy becomes an important task to slow down the pace of global warming and maintain sustainable development of human society. China is fully aware of the importance, severity and urgency of tackling climate changes. Six ministries and commissions including Ministry of Science and Technology, China Meteorological Administration, NDRC and SEPA issued the first National Assessment Report of Climate Change in the end of 2006. China issued National Climate Change Program in June, 2007 and Chinese Academy of Science proposed the strategic target of developing low-carbon economy in the China Sustainable Development Report 2009 issued in March, 2009. The target is to reduce carbon emission per unit of GDP by about $50 \%$ by 2020. It is of great significance for Guangxi Beibu Gulf Economic Zone to develop low-carbon economy in order to promote the transformation of traditional industries, eliminate conflicts between industrial structures and environment, change the situation of extensive growth, reduce carbon emission and to protect ecological environment and achieve the target of sustainable development in the region.

\section{Evolution of Industrial Structures and Development of Low-Carbon Economy}

The term "industrial structures" appeared in the middle of 1950s. It refers to the technical and economic relationship between different industries and their 
proportions in economic activities. Industrial structures are the result of previous economic growth, the base of future economic growth and the fundamental factors for economic development. Evolution of industrial structures is mainly from lower grade to higher grade and towards sophistication and rationalization. Regions with low energy consumption and high economic benefits usually have relatively reasonable industrial structures. Secondary industries have most significant influence on carbon emission intensity, followed by primary industries and tertiary industries. Some low carbon scholars hold that industrial restructuring should lay emphasis on restructuring of secondary industries and development of tertiary industries. However, carbon emission does not decrease along with increasing scales of tertiary industries in China. The problem lies in structures inside each industry. Whether industrial structures are reasonable is related to the potential of sound and rapid development of regional economy, which coincides with the target of $10 \mathrm{w}$ carbon economy. That is, reasonable industrial structures can promotederelopment of low-carbon economy which, in turn, boost the upgrading and optimizing of industrial structures. They interplay and affect each other and together push sustainable development of economy.

Evolution of industrial structures can be decomposed into four stages according to Rostovian take-off model. The first stage was transition from conventional agriculture to light textile industry. Energy demand increased slowly and carbon emission showed no influence on economic growth incthis stage. The second stage was transition from light textile industry to heavy industry. Energy demand increased sharply and carbon emission became one of restrictive factors for economic growth during this period. The third stage was transition from raw material industry featuring high carbon and high emission to manufacturing industries such as processing and assemble Stable demand for energy moderated the increase of carbon emission. The fourth stage is a technology intensive stage. Science and technology beeomes key elements while effective utilization of energy improves significantly and carbon emission gradually decreases and keeps at a relatively stable level.

\section{Status Analysis on Carbon Emission in Guangxi Beibu Gulf Economic Zone}

This paper calcutares and analyzes carbon emissions based on data from Guangxi Statistical Yearbook 2014 and China Energy Statistical Yearbook and on the energy consumption default values from IPCC's carbon emission coefficients of fossil energy. According to actual requirements of this research and real conditions of GuangX1 Beibu Gulf Economic Zone, we just take carbon emissions from end-use of energy into account when calculating carbon emissions. For energy sources, we just consjaer coal, oil and natural gas. Carbon emissions from energy loss during process and conversion, transport and distribution are omitted. We employ a carbon emission formula certified by IPCC, and based on the local conditions, to calculate carbon emissions during 2006 and 2013 in Guangxi Beibu Gulf Economic Zone, where the carbon emission coefficient is IPCC coefficient (see Table 4-3).

$$
P_{t}=a P_{t a}+b P_{t b}+c P_{t c}
$$

where $\mathrm{P}$ denotes total carbon emissions; $\mathrm{t}$ indicates time; and $\mathrm{P}_{\mathrm{t}}$ represents total carbon emissions in the year of t. a, b and $\mathrm{c}$ is carbon emission coefficient of coal, oil and natural gas respectively. $\mathrm{P}_{\mathrm{ta}}, \mathrm{P}_{\mathrm{tb}}$ and $\mathrm{P}_{\mathrm{tc}}$ signifies the consumption (Unit: standard coal) of coal, oil and natural gas respectively in the year of $t$. 
Table 1. Carbon Emission Coefficient

\begin{tabular}{cccc}
\hline Energy sources & Coal & Oil & Natural gas \\
\hline Coefficient & 0.7559 & 0.5857 & 0.4483 \\
\hline
\end{tabular}

\subsection{Total Carbon Emission Analysis}

Carbon emissions from 2006 to 2013 are summarized in Table 2 as below after calculating by the equation above based on Guangxi Statistical Yearbook 2014.

Table 2. Carbon Emissions in Guangxi Beibu Gulf Economic Zone in 2006-2013

\begin{tabular}{ccccccccc}
\hline Year & 2006 & 2007 & 2008 & 2009 & 2010 & 2011 & 2012 & 2013 \\
\hline $\begin{array}{c}\text { Carbon emissions } \\
(10,000 t)\end{array}$ & 1306.6 & 1628.5 & 1684.7 & 1908.0 & 1936.9 & 2182.1 & 2329.2 & 2572.6 \\
\hline
\end{tabular}

Data source: Guangxi Statistical Yearbook 2014

As shown in Table 2, carbon emissions increased every year from 2006 to 2013 in Guangxi Beibu Gulf Economic Zone, especially guring 2006 and 2007, 2008 and 2009, 2010 and 2011, 2011 and 2012 as well as 2012 and 2013 which witnessed rapid increase in carbon emissions due to fast rising energy consumption. Carbon emissions increased moderately during the period from 2007 to 2008 and from 2009 to 2010. According to above analysis on status and features of the industrial structure in the region, secondary indastries feature high carbon and high energy consumption, thus they are the key to energy conservation and emission reduction.

\subsection{Carbon Emission Intensity Analysis}

Carbon emission,intensity refers to the carbon emissions per unit of GDP. It is an index denoting the relationship between economic growth and carbon emission. The calculation formula is shown as: carbon emission intensity=total carbon emissions/GDP. A region is deemed as success in developing low-carbon economy if its economic volumes increase with decreasing carbon emissions per unit of GDP. Results are summarized in Table 3 based on data in Table 2 and Guangxi Statistical Yearbook 2014.

Table 3. Carbon Emission Intensity in Guangxi Beibu Gulf Economic Zone in 2006-2013

\begin{tabular}{ccccccccc}
\hline Year & 2006 & 2007 & 2008 & 2009 & 2010 & 2011 & 2012 & 2013 \\
\hline $\begin{array}{c}\text { GDP(100 } \\
\text { milion Yuan) }\end{array}$ & 2043.56 & 2516.70 & 3090 & 3480.84 & 4275.37 & 5281.97 & 5901.17 & 6600.52 \\
$\begin{array}{c}\text { Carbon } \\
\text { emission } \\
\text { intensity }\end{array}$ & 0.633 & 0.647 & 0.545 & 0.548 & 0.453 & 0.413 & 0.334 & 0.383 \\
\hline
\end{tabular}

Data source: Guangxi Statistical Yearbook 2014

As shown in Table 3, carbon emission intensity showed a roughly downward trend in Guangxi Beibu Gulf Economic Zone, which means the region has made certain achievements in developing low-carbon economy. He Jiankun et al. believed that absolute reduction of carbon emissions can be achieved only when decreasing scale of carbon emission intensity is larger than growth rate of GDP. But, based on calculation, the decreasing scale of carbon emission intensity was smaller than growth rate of GDP every year from 2006 to 2013 in the region, which indicated that the region failed to realize the absolute reduction of carbon emissions. This is 
inseparable from the industrial structures as its dominant industry is still secondary industries which feature "high carbon, high emission and high energy consumption". Consumption of high-carbon energy is the main driving force of increasing carbon emissions. It is a direct restriction to achievement of the target of energy conservation and emission reduction in the region. Therefore, it is particularly urgent to develop low-carbon economy.

\section{Grey Correlation Analysis between Industrial Structures and Carbon Emission in Guangxi Beibu Gulf Economic Zone}

\subsection{Methodologies}

Grey system theory was proposed by Chinese scholar Prof. Deng Julong in 1982 as a kind of new studies focusing on the system with few data, poor information and uncertainty questions. The objects of these studies are uncertain systems with known information and unknown information, and generate and develop the known information to correctly describe the system evolution principles. "Grey" represents known information and unknown information and the corresponding system is called grey system. Research contents of grey system thepry include system analysis, data generation, modeling, forecast, decision-makıng and control. It has been applied to military, economy, industry, agriculture, ecology, meteorology, earthquake and education. Generally, regression analysis and variance analysis are two methods used in abstract systenas. But these methods have strict requirements for data. A plenty of sample data are needed and these data should be subject to certain canonical distribution. Rovever, there are limited statistical data about industries and energy in Guangxi.Beibu Gulf Economic Zone. And some information is clear and definite while others are not. Grey correlation model can overcome these shortcomings and the calculation is relatively easy and effective to analyze relationship between industrial structures and carbon emission.

\subsection{Modeling}

In grey correlation models, calculation steps are as below:

(1) Reference number series $F_{0}(k)$ and comparison number series $F_{i}(k)$ clearing reflecting characteristios of systems:

where, $\mathrm{F}_{0}=\left\{\mathrm{F}_{0}(\mathrm{k}) \uparrow \mathrm{k}=1,2,3 \ldots \ldots \mathrm{n}\right\}$

$\mathrm{F}_{\mathrm{i}}=\left\{\mathrm{F}_{\mathrm{i}}(\mathrm{k}) \wedge \mathrm{k}=1,2,3 \ldots \ldots \mathrm{n} ; \mathrm{i}=1,2,3 \ldots \ldots \mathrm{m}\right\}$

(2) Standardízed treatment of number series (non-dimensional treatment)

Direct comparison between index data is unfulfillable as they have different meanings and dimensions. For convenient comparison and calculation, nondimensional treatment should be done to data.

$$
\begin{aligned}
\mathrm{F}_{\mathrm{i}}^{\prime} & =\frac{F_{i}}{F_{i}(1)}=\left\{\frac{F_{i}(1)}{F_{i}(1)}, \frac{F_{i}(2)}{F_{i}(1)}, \frac{F_{i}(3)}{F_{i}(1)}, \ldots \ldots, \frac{F_{i}(n)}{F_{i}(1)}\right\} \\
& =\left\{F_{i}^{\prime}(1), F_{i}^{\prime}(2), F_{i}^{\prime}(3), \ldots \ldots, F_{i}^{\prime}(n)\right\}, \mathrm{i}=0,1,2,3 \ldots \ldots \mathrm{m}
\end{aligned}
$$

(3) Calculating difference number series

$$
\begin{aligned}
\triangle \mathrm{F}_{\mathrm{I}}(\mathrm{k}) & =\left|F_{0}^{\prime}(k)-F_{i}^{\prime}(k)\right| \\
& =\left\{\left|F_{0}^{\prime}(1)-F_{i}^{\prime}(1)\right|,\left|F_{0}^{\prime}(2)-F_{i}^{\prime}(2)\right|,\left|F_{0}^{\prime}(3)-F_{i}^{\prime}(3)\right|, \ldots \ldots,\left|F_{0}^{\prime}(n)-F_{i}^{\prime}(n)\right|\right\}, \mathrm{i} \\
& =1,2,3, \ldots \ldots . \mathrm{m} ; \mathrm{k} \\
& =1,2,3 \ldots \ldots . \mathrm{n}
\end{aligned}
$$

(4) Calculating maximum difference $(\max )$ and minimum difference $(\min )$

where,

$$
\max =\max _{i} \max _{k} \Delta \mathrm{F}_{\mathrm{I}}(\mathrm{k})
$$


$\min =\min _{i} \min _{k} \Delta \mathrm{F}_{\mathrm{I}}(\mathrm{k}), \mathrm{i}=1,2,3, \ldots \ldots \mathrm{m} ; \mathrm{k}=1,2,3 \ldots \ldots \mathrm{n}$

(5) Calculating correlation coefficient $\varepsilon_{i}(k)$. It indicates the relevancy between comparison number series and reference number series at each time point, so there are more than one coefficient.

$\varepsilon_{i}(k)=\frac{\min +\rho \max }{\Delta F_{i}(k)+\rho \max }$

where, $\rho$ is resolution ratio in the probability space $(0,1)$. Generally, the value of $\rho$ is 0.5 .

(6) Calculating relevancy $r_{i}$

There several correlation coefficients and they are different from each other. We take the average value of these correlation coefficients, namely the relevancy, for convenient comparison.

Where, the relevancy:

$r_{i}=\frac{1}{n} \sum_{k=1}^{n} \varepsilon_{i}(k), \quad \mathrm{i}=1,2,3, \ldots \ldots \mathrm{m}$

At last, we need to compare the relevancy. Larger value of relevancy indicates higher level of similarity between comparison number series and reference number series.

\subsection{Empirical Analysis}

Different industries differ in energy consumption and the consequential carbon emissions. Thus it is necessary to analyze the relationship between industrial structures and carbon emissions in Guangxi) Beibu Gulf Economic Zone. Here, total carbon emissions are regarded as reference number series $\mathrm{F}_{0}$ and proportions of three industries among local GDP areuregarded as comparison number series $F_{i}$ from 2006 to 2013. Then calculation formulas described above are used to define the relationship between industrial structures and carbon emissions in the region. Data are summarized n Table 4 as blow:

Table 4. Proportion of Output Values of Three Industries and Total Carbon Emissions in Guangxi Beibu Gulf Economic Zone in 2006-2013

\begin{tabular}{cccccccccc}
\hline Year & 2006 & 2007 & 2008 & 2009 & 2010 & 2011 & 2012 & 2013 & code \\
\hline $\begin{array}{c}\text { Total carben } \\
\text { emissions }\end{array}$ & 1306.6 & 1628.5 & 1684.7 & 1908.0 & 1936.9 & 2182.1 & 2329.2 & 2572.6 & F0 \\
$\begin{array}{c}(10,000 \mathrm{t}) \\
\begin{array}{c}\text { Output values of } \\
\text { primary industries } \\
(\%)\end{array}\end{array}$ & 21.8 & 21.3 & 20.7 & 18.8 & 17.5 & 17.5 & 16.7 & 16.3 & F1 \\
$\begin{array}{c}\text { Output values of } \\
\text { secondary } \\
\text { industries (\%) } \\
\text { Output values of } \\
\text { tertiary industries } \\
(\%)\end{array}$ & 38.6 & 41.6 & 43.3 & 43.6 & 47.1 & 48.4 & 47.9 & 47.7 & F2 \\
\hline
\end{tabular}

Data source: Guangxi Statistical Yearbook 2014 and Table 2

Correlation coefficients are calculated by the formula (1), (2), (3), (4), (5), (6) and (7) between proportion of output values of three industries and total carbon emissions in the region and summarized in Table 5 as follows: 


\section{Table 5. Correlation Coefficients between Proportion of Output Values of Three Industries and Total Carbon Emissions in Guangxi Beibu Gulf Economic Zone}

\begin{tabular}{cccc}
\hline \multirow{2}{*}{ Year } & \multicolumn{3}{c}{ Coefficient } \\
\cline { 2 - 4 } & $\varepsilon_{1}(k)$ & $\varepsilon_{2}(k)$ & $\varepsilon_{3}(k)$ \\
\hline 2006 & 1 & 1 & 1 \\
2007 & 0.670 & 0.782 & 0.663 \\
2008 & 0.650 & 0.792 & 0.619 \\
2009 & 0.504 & 0.645 & 0.547 \\
2010 & 0.473 & 0.701 & 0.508 \\
2011 & 0.413 & 0.592 & 0.430 \\
2012 & 0.379 & 0.530 & 0.407 \\
2013 & 0.333 & 0.455 & 0.365
\end{tabular}

By the formula (8), proportion of output values of primary, secondaty and tertiary industry, namely $\mathrm{F}_{1}, \mathrm{~F}_{2}$ and $\mathrm{F}_{3}$, has correlation coefficient with carbon emissions $\mathrm{F}_{0}$ as follows respectively: $r_{1}=0.553, r_{2}=0.687, r_{3}=0.567$, whigh is subject to the following relation: $r_{2}>r_{3}>r_{1}$. That is, among three industries, the secondary industries have the highest correlation with total darbon emissions. Secondary industries impact carbon emissions mos significantly and play a dominant role in developing low-carbon economy in the region. Tertiary industries have a lower correlation with total carbon emissions and the primary industries is least correlated with total carbon emissions. This result well coincides with the current "tertiary, primary and secondary" production value pattern among three industries in the region, which indicates that industrial structures are closely related with carbon emissions. Especially, secondary industries have most significant impact on carbon emissions, followed by tertiary and primary industries.

\section{Result Analysís}

This research finds that carbon emissions are closely related with industrial structures in Guangxi Beibu Gulf Economic Zone, and the relationship may vary with economic development and features of industrial structures. For this reason, responsible authorities are suggested to take into account following factors when designing Aindustrial policies for the region to reduce carbon emissions. First, accelerate imdustrial restructuring and promote upgrading of low-carbon technologies in secondary industries. The industrial structure is in a "tertiary, primary and secondary" production value pattern in the region, and secondary industries are the main driving force to local economic development and impact carbon emissions most significantly. Therefore, responsible authorities should take measures to shut down or reorganize enterprises with serious pollution and low benefits and weed out facilities with high energy consumption, high pollution and high emission. Low-carbon technologies should be introduced to upgrade production equipment and industry scales and agglomeration effect should be enhanced. Low-carbon reform should be performed in secondary industries in order to step on a low-carbon development path. Second, more attention should be paid to development of tertiary industries. Their proportion among gross economic values should be increased gradually. Certain considerations have been given to tertiary industries in the region, but there is still a long way to go before the proportion of their output values reach $66 \%$ just as in developed countries. For this reason, measures should be taken to increase the proportion of output values of tertiary 
industries, to optimize their internal structures, and to realize the overall industrial restructuring in the region. Third, low-carbon effect of agriculture should be fortified. A major measure is to decrease the proportion of agriculture during the process of industrial restructuring in Beibu Gulf Economic Zone. Responsible authorities are expected to give full play to low-carbon effect of agriculture through low-carbon technical reform and enhancement of carbon sink function, realizing a low-carbon agriculture.

For development of low-carbon economy in Guangxi Beibu Gulf Economic Zone, the key is law and policy guarantee, technical innovation and public participation. In the aspect of law, a legal system for low-carbon economy can be established based on the local reality. Implementation of related laws such as Law on Energy Saving should be supervised and inspected with more efforts, and a long-term mechanism should be established and improved to supervise efforts for energy saving and emission reduction. For polices, plans should be designed for the low-carbon development in the medium and long term. Economic incentive polices can be taken to push low-carbon development. These polices includectax incentives for renewable energy sources, special funds for development of renewable energy sources and subsidies for personal investment or participation in investment on renewable energy sources. In terms of technical innovation, existing low -carbon technologies should be integrated. Power should be generated by consuming rich carbon-free energy sources such as wind force, water rèsource and solar energy. Ecological tourism should be developed. Advanded biopharmacy technologies should be introduced to realize deep processing gf marine froducts and appreciation of basic values. Accelerate training and introducing of technical personnel who are specialized in low-carbon technologies. Set'special funds for research and development of low-carbon technologies Beibu Gulf Economic Zone should enhance cooperation with ASEAN countries in low-carbon fields and build corresponding cooperative mechanism. For public participation, strengthen lowcarbon education and expand ecologieal and humanistic quality education. Channels such as network TV, broadcast, newspaper and books should be used for these education goals, developing the public's awareness of environmental protection.

\section{2 Changing Consumption Patterns}

For individuals people should change consumption patterns and innovate new life styles in the aspect of clothing, food, housing and transportation. First, buy unnecessary clothes as less as possible and recycle unwanted clothes. Dry wet clothes in the sun instead of washing machine. Second, prefer vegetables to meat as your meals and do not waste. Choose low carbon diets and reduce consumption of carbohydrates. Third, turn off lights and computers when leaving. Save electricity and water. Classify garbage, use energy saving lamps, purchase green buildings, and take the stairs instead of elevators. Fourth, reduce unnecessary travels, travel by bike and bus or on foot. If possible, do not drive cars. Purchase cars with small displacements. At last, everyone should do their best to practice low-carbon consumption and promote development of low-carbon economy.

\section{References}

[1] S. Zhou, L. Mi, H. Chen, Y. Geng, "Building detection in Digital surface model, 2013 IEEE International Conference on Imaging Systems and Techniques (IST)”, Oct. (2012).

[2] J. He, Y. Geng, K. Pahlavan, "Toward Accurate Human Tracking: Modeling Time-of-Arrival for Wireless Wearable Sensors in Multipath Environment", IEEE Sensor Journal, vol. 14, no. (11), pp. 3996-4006, Nov. (2014).

[3] Lv Z, Halawani A, Fen S. Touch-less Interactive Augmented Reality Game on Vision Based Wearable Device[J]. Personal and Ubiquitous Computing, (2015), vol. 19, no. 3, pp. 551-567. 
[4] G. Bao, L. Mi, Y.Geng, M. Zhou, K. Pahlavan, "A video-based speed estimation technique for localizing the wireless capsule endoscope inside gastrointestinal tract", 2014 36th Annual International Conference of the IEEE Engineering in Medicine and Biology Society (EMBC), Aug. (2014).

[5] D. Zeng, Y. Geng, "Content distribution mechanism in mobile P2P network", Journal of Networks, vol. 9, no. 5, pp. 1229-1236, Jan. (2014).

[6] Gu W, Lv Z, Hao M. Change detection method for remote sensing images based on an improved Markov random field[J]. Multimedia Tools and Applications, (2015), pp. 1-16.

[7] Chen Z, Huang W, Lv Z. Towards a face recognition method based on uncorrelated discriminant sparse preserving projection[J]. Multimedia Tools and Applications, (2015), pp. 1-15.

[8] J. Hu and Z. Gao. Distinction immune genes of hepatitis-induced heptatocellular carcinoma[J]. Bioinformatics, (2012), vol. 28, no. 24, pp. 3191-3194.

[9] Su T, Wang W, Lv Z. Rapid Delaunay triangulation for randomly distributed point cloud data using adaptive Hilbert curve[J]. Computers \& Graphics, (2016), 54: pp. 65-74.

[10] $\mathrm{Gu} \mathrm{W,} \mathrm{Lv} \mathrm{Z,} \mathrm{Hao} \mathrm{M.} \mathrm{Change} \mathrm{detection} \mathrm{method} \mathrm{for} \mathrm{remote} \mathrm{sensing} \mathrm{images} \mathrm{based} \mathrm{on} \mathrm{an} \mathrm{improved}$ Markov random field[J]. Multimedia Tools and Applications, (2015), pp. 1-16.

[11] Lv Z, Tek A, Da Silva F. Game on, science-how video game technology may help biologists lackle visualization challenges[J]. PloS one, (2013), vol. 8, no. 3, 57990.

[12] Chen Z, Huang W, Lv Z. Towards a face recognition method based on uncorrelated discrimmant sparse preserving projection[J]. Multimedia Tools and Applications, (2015) $\mathrm{pp}_{\mathrm{s}} 1-15$.

[13] J. D, Y. X, Han Y. Collaborative multi-hop routing in cognitive wireless networks J]. Wireless Personal Communications, (2015), pp. 1-23.

[14] Lv Z, Tek A, Da Silva F. Game on, science-how video game technology may help biologists tackle visualization challenges[J]. PloS one, (2013), vol. 8, no. 3, pp. 57990

[15] Jiang D, Xu Z, Lv Z. A multicast delivery approach with minimum energy consumption for wireless multi-hop networks[J]. Telecommunication Systems, (2015), pp. 1_12.

[16] Fu C, Zhang P, Jiang J. A Bayesian approagch for sleep and wake erassification based on dynamic time warping method[J]. Multimedia Tools and Applications, (2015), pp. 1-20.

[17] Lv Z. Wearable smartphone: Wearable Gybrid framewo R for hand and foot gesture interaction on smartphone[C]//Computer Vision Workshops (ICCVW), 2013 IEEE International Conference on. IEEE, (2013), pp. 436-443.

[18] Lin Y, Yang J, Lv Z. A Self-Assessment Stereo Capture Model Applicable to the Internet of Things[J]. Sensors, (2015), vol. 15, no. 8, pp. 20925-20944
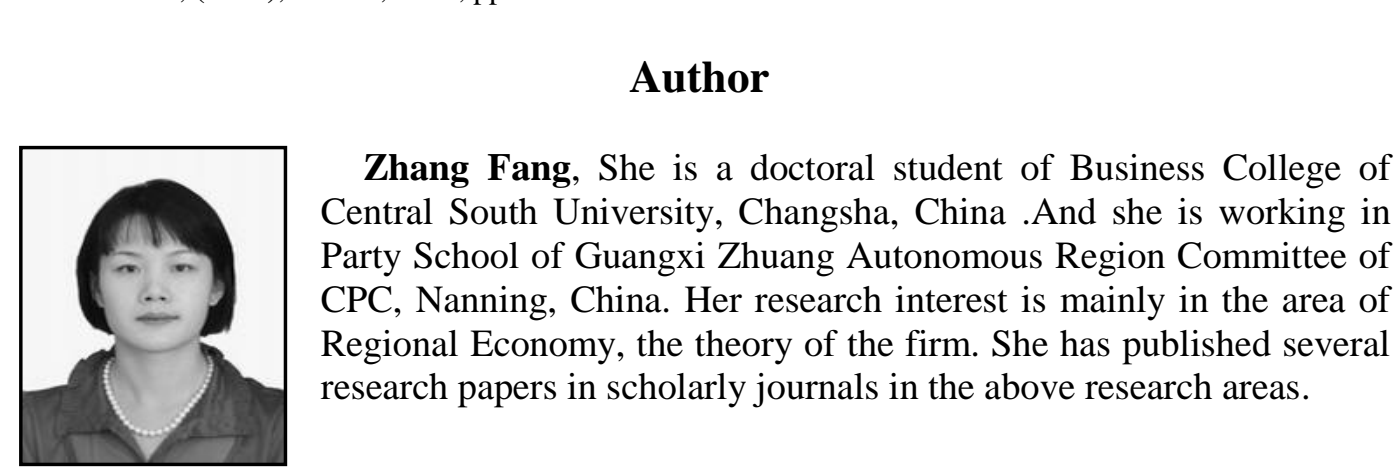